\title{
Myelodysplasia-associated Sweet's syndrome: clinical and laboratory presentation and response to thalidomide
}

\author{
Bartlomiej Wawrzycki ${ }^{1 *}$, Dariusz Jawniak ${ }^{2}$, Aldona Pietrzak ${ }^{1}$, Justyna Szumilo ${ }^{3}$, Dorota Krasowska ${ }^{1}$ \\ ${ }^{1}$ Chair and Department of Dermatology, Venereology and Pediatric Dermatology, Medical University of Lublin, Lublin, Poland \\ ${ }^{2}$ Department of Hemato-Oncology and Bone Marrow Transplantation, Medical University of Lublin, Lublin, Poland \\ ${ }^{3}$ Chair and Department of Clinical Pathomorphology, Medical University of Lublin, Lublin, Poland
}

\section{Introduction}

Sweet's syndrome (SS) is an uncommon disease of not entirely understood pathophysiology. Depending on the clinical context, it can be classified into classic SS, malignancy-associated SS (MASS) and drug-induced SS (DISS) [1]. The classic variant is the most frequent, accounting for more than $50 \%$ of cases. On average, $20 \%$ of SS patients have an underlying malignancy, and $10 \%$ belong to the drug-induced subtype (DISS) [1]. Since prognosis depends on comorbid conditions, it is essential to establish a proper diagnosis.

\section{Case report}

A 73-year-old patient was referred to our clinic because of an almost 3-year history of recurrent bouts of tender papulo-nodules and plaques. Two skin biopsies performed earlier (2014) had described lymphocytic perivascular infiltrates. He was diagnosed as having cutaneous lupus erythematosus and was treated with methylprednisolone at daily doses ranging from 16 to $32 \mathrm{mg}$. Initially, there was a prompt clinical response and long-lasting remission. Unfortunately, over time the disease became increasingly severe with multiple relapses and reduced symptom-free intervals. He received hydroxychloroquine at a dose of 200 mg per day but with no improvement. On admission, the patient presented with widespread nodules and plaques with targetoid-appearance (Figure 1). There were also aphthous-like ulcers on the oral mucosa (Figure 2).

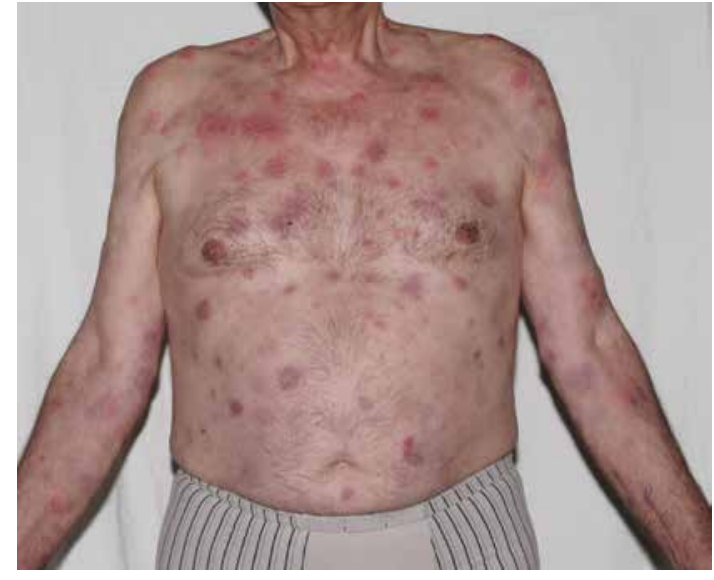

Figure 1. Widespread nodules and plaques with targetoid-appearance

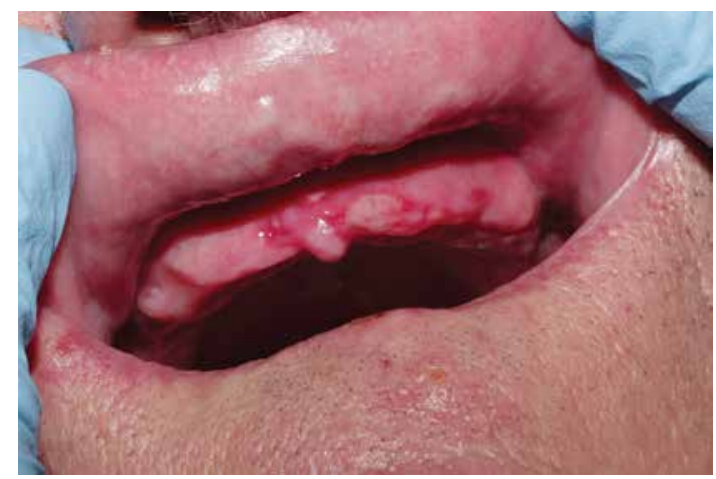

Figure 2. Aphthous-like ulcers on the oral mucosa

\footnotetext{
*Address for correspondence: Bartlomiej Wawrzycki, Department of Dermatology, Venereology and Pediatric Dermatology, Medical University of Lublin, Staszica $11 \mathrm{H}$, 20-081, Lublin, Poland, e-mail: bartekwawrzycki@gmail.com Received: 22.08.2020 Accepted: $29 \cdot 10.2020$
} 
Table I. Patient's blood morphology during the curse of the disease

\begin{tabular}{|c|c|c|c|c|c|c|c|c|c|c|}
\hline Date & 2014 & 10.2016 & 08.2017 & 10.2017 & 11.2017 & 03.2018 & 05.2018 & 01.2019 & 06.2019 & 09.2019 \\
\hline $\begin{array}{l}\text { Course of } \\
\text { disease, in- } \\
\text { vestigations, } \\
\text { and treat- } \\
\text { ment }\end{array}$ & $\begin{array}{l}\text { Onset } \\
\text { of } \\
\text { Sweet's } \\
\text { syndro- } \\
\text { me }\end{array}$ & \multicolumn{2}{|c|}{$\begin{array}{l}\text { Diagnostic workup } \\
\text { (i.e. skin biopsy, } \\
\text { exclusion of solid } \\
\text { tumors, IBD, auto- } \\
\text { immune conditions } \\
\text { and infections). } \\
\text { Corticosteroid/dap- } \\
\text { sone regimen* }\end{array}$} & $\begin{array}{l}\text { Bone } \\
\text { marrow } \\
\text { aspirate } \\
\text { and } \\
\text { trephine } \\
\text { biopsy } \\
\\
\text { MDS- } \\
\text {-MLD }\end{array}$ & $\begin{array}{l}\text { Resolution } \\
\text { of skin } \\
\text { symptoms. } \\
\text { Tapering } \\
\text { of predni- } \\
\text { sone* }\end{array}$ & & & & & \\
\hline Thalidomide & - & - & - & - & $100 \mathrm{mg} / \mathrm{d}$ & $50 \mathrm{mg} / \mathrm{d}$ & $25 \mathrm{mg} / \mathrm{d}$ & $50 \mathrm{mg} / \mathrm{d}$ & $25 \mathrm{mg} / \mathrm{d}$ & $25 \mathrm{mg} / \mathrm{d}$ \\
\hline $\mathrm{Hb}[\mathrm{dL}]$ & & 10.7 & 10.8 & & 13.6 & 13.2 & 12.6 & 12.8 & 13.7 & 13.3 \\
\hline WBC $[\mathrm{G} / \mathrm{L}]$ & & 3.63 & 7.77 & & 7.97 & 5.71 & 6.46 & 4.96 & 5.45 & 4.88 \\
\hline ANC [G/L] & & 1.64 & 5.0 & & 6.27 & 3.08 & 3.45 & 1.88 & 3.93 & 2.03 \\
\hline PLT [G/L] & & 148 & 241 & & 176 & 208 & 192 & 209 & 153 & 153 \\
\hline
\end{tabular}

*Detailed description in the text; IBD - inflammatory bowel disease; MDS-MLD - myelodysplastic syndrome with multilineage dysplasia; Hb - hemoglobin; WBC - white blood cells; ANC - absolute neutrophil count; PLT - platelets

While disease flared, findings from laboratory tests showed an elevated erythrocyte sedimentation rate (ESR): $120 / \mathrm{h}$ and C-reactive protein $(0-5 \mathrm{mg} / \mathrm{L}):$ 78.4$-137.1 \mathrm{mg} / \mathrm{L}$. During a one-year observation period, repeated blood tests revealed a tendency towards anemia, and leukopenia with neutropenia (Table I). Interestingly, besides such laboratory peculiarities (leukopenia with neutropenia), only a few exacerbations were accompanied by raised temperature. Tumor markers and electrophoresis were within normal values. Screening for autoimmune diseases (ANAs, ENAs, anti-double-stranded DNA, anticardiolipin antibodies, c-ANCAs, p-ANCAs) yielded negative results. Serological tests for Yersiniosis anti-Yersinia enterocolitica IgA, IgG antibodies were negative. Neither abdominal not chest computed tomography scans were remarkable. Results of gastroscopy and colonoscopy were also inconspicuous. We performed two consecutive skin biopsies $(2016,2017)$ showing dermal infiltrates composed mainly of neutrophils, eosinophils, and myeloid cells (Figures $3 A, B$ ): lesional infiltrate labeled with myeloperoxidase and CD15 (polymorphonuclear neutrophils) and CD68 (myeloid cells). There was also some admixture of T lymphocytes $\left(\mathrm{CD} 45^{+} \mathrm{CD}^{+}\right.$) (Figure $\left.3 \mathrm{C}\right)$.

Our patient met the criteria for SS. He had both major criteria (clinical manifestations, neutrophilic infiltrate without leucocytoclasia) and two minor criteria (associated disease, response to corticosteroid therapy). Because of the chronic, recurrent course and atypical clinical and laboratory features, the diagnostic work-up was broadened to include bone marrow aspirate smear and trephine biopsy. Bone marrow aspirate showed dysplasia of $10 \%$ of myeloid lineage cells (Figure 3D), whereas trephine biopsy revealed hypercellularity and features of multilineage dysplasia. Cytogenetic examination of bone marrow found normal karyotype. Later, based on the investigations above and laboratory parameters, MDS with multilineage dysplasia (MDS-MLD) was diagnosed.

Initially, we started him on oral prednisone $0.5 \mathrm{mg} / \mathrm{kg} /$ /day, with a good clinical response. Unfortunately, there were flares of SS on doses below $20 \mathrm{mg}$ per day. Then, dapsone $(100 \mathrm{mg} /$ day) was added for three months, but with no benefit. Finally, we decided to give our patient $100 \mathrm{mg}$ thalidomide/day along with a prophylactic dose of acetylsalicylic acid. Thalidomide ( $\mathrm{TH}$ ) led to complete resolution of the disease, and allowed for tapering and finally stopping steroids within one month. Due to somnolence and constipation, we had to reduce the dose to $50 \mathrm{mg} /$ day after two months. During the whole observation period, we did not observe any adverse events. Importantly, TH also stabilized the patient's blood morphology. Nevertheless, we were unable to discontinue the $\mathrm{TH}$ because of recurrences of skin eruption. Currently, he is still on $25 \mathrm{mg}$ of thalidomide every other day, which controls the disease (Table I).

\section{Discussion}

Sweet's syndrome (acute febrile neutrophilic dermatosis) belongs to a heterogeneous group of neutrophilic dermatoses (NDs), which are characterized by histologically evidenced neutrophilic infiltrate [2]. Hematologic disorders account for $85 \%$ of MASS. The most prevalent are acute myeloid leukemia (AML) and myelodysplastic syndromes (MDS) [3]. The less frequently reported ones are myeloproliferative diseases, CLL, and paraproteinemias. Solid tumors constitute $7-15 \%$ of associated cancers [1]. Myelodysplastic syndromes are a group of clonal hematopoietic stem 


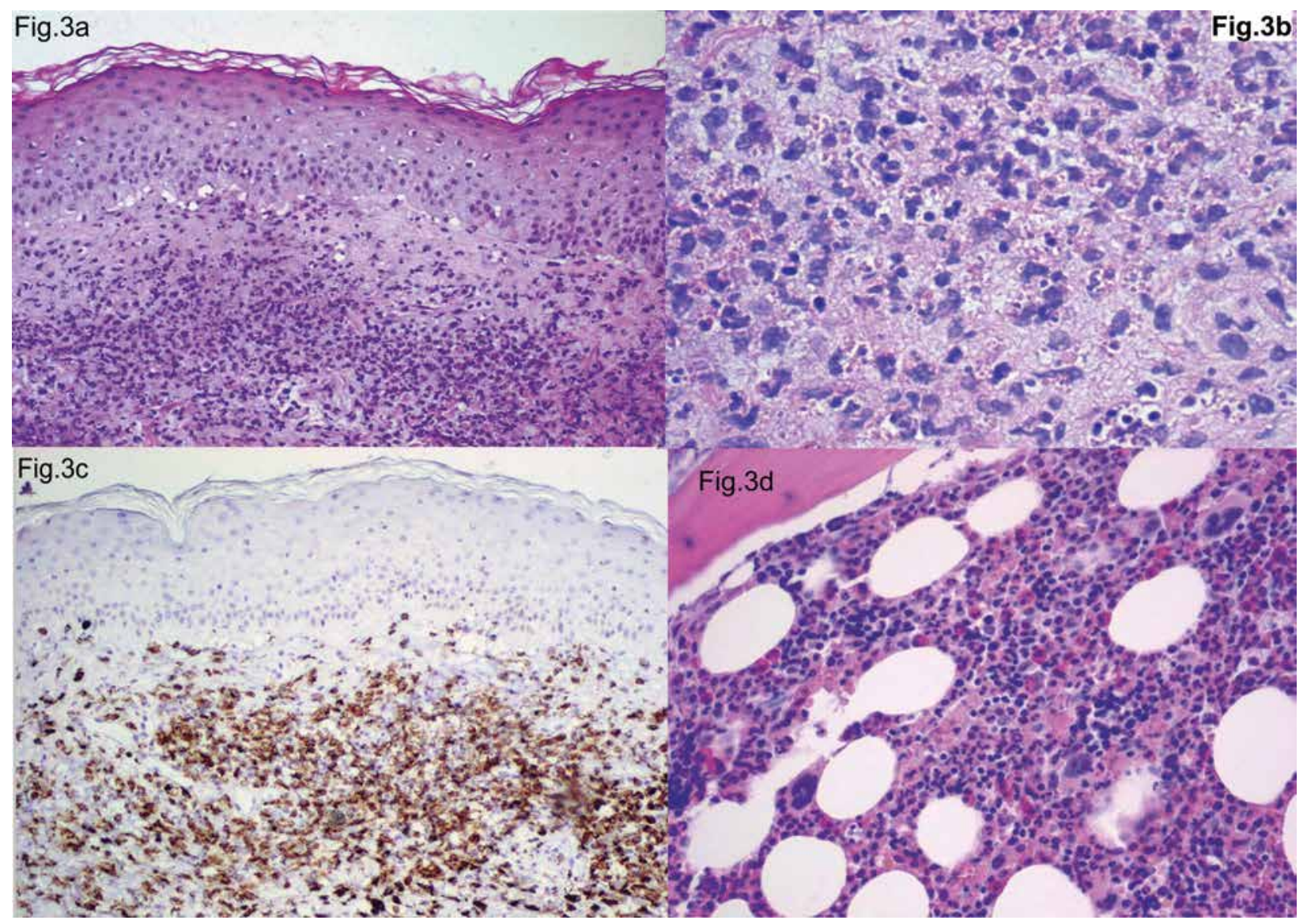

Figure 3A, B. Infiltration of the skin composed of neutrophils, eosinophils and myeloid cells; C. The lesional infiltrate showing positive immunostaining for CD68; D. Myelodysplastic syndrome with multilineage dysplasia in trephine biopsy of patients with Sweet's syndrome

cell diseases with cytopenia(s) and dysplastic features in one or more myeloid lineage [4].

Our patient presented with lesions of widespread distribution (Figure 1), which is considered by some authors to be a potential sign of underlying malignancy [1]. Notably, crops of cutaneous lesions were accompanied by oral ulcerations (Figure 2), which are not only extremely rare in SS but also possibly indicative of MASS [5]. Malaise and low-grade fever parallelled the exacerbations, but without arthralgias or other constitutional symptoms. Lack of joint complaints and afebrile disease have both been found to be more prevalent in the paraneoplastic variant [6]. Unfortunately, besides anemia, only a few findings have been consistently reported to differ between cancer-associated SS and the classic idiopathic form [2]. Data from case series indicates, however, that a combination of chronicity and refractoriness to treatment [7] plus initially lymphocytic infiltrates on skin biopsy, especially in older males, could potentially indicate a distinct group of SS patients at higher risk of developing MDS [8, 9]. Clearly, in our case, there was gradually increasing anemia, and the disease had a chronic, remittent course. Moreover, the first biopsies showed predominantly lymphocytic infiltrate. Our findings seem to parallel observations from published case series, which have described 'initial' lymphocytic and 'late' neutrophilic patterns [8].

Many studies have revealed a strong association between myelodysplasia and autoimmune and inflammatory conditions (AIMs) [10]. AIMs can appear before, during, or after the diagnosis of MDS [10]. In the lymphocytic variant of MDS-associated SS, cutaneous disease has been found to appear between 6 months and 8 years (median 3.5 years) $[8,9]$ before myelodysplastic syndrome. Patients with typical histopathology described by Kulasekararaj et al. [7] had MDS diagnosed at a median of 1.5 years following the development of SS.

Our findings are in agreement with previous studies in showing that skin lesions of SS can precede by months, or years, a diagnosis of MDS. In the presented patient, it was three years from the beginning of the SS to the confirmation of MDS.

The pathogenesis of SS is complex and multifactorial. Recent research has revealed that neutrophil-rich cutaneous inflammation might be a consequence of an overactive 
innate immune system [11] and excessive synthesis of interleukin 1 (IL-1) family members [12, 13]. Paraneoplastic inflammation implicated in MDS includes abnormal expression of distinct inflammatory cytokines and chemokines, which are produced by the immune, stromal, and malignant cells. There are also qualitative and quantitative differences in inflammatory cell recruitment [14]. Remarkably aberrant innate immune activation (specifically, NLRP3 inflammasome formation and pyroptosis) is now believed also to be a key driver of ineffective hematopoiesis in MDS [15]. In the setting of cancer-associated Sweet syndrome, the underlying myeloid dysfunction may disrupt networks of cytokine and stimulating factors, which in turn could exaggerate neutrophil chemotaxis and activation [16].

Thalidomide and its derivates belong to a group of therapeutic agents collectively called immunomodulatory drugs (IMIDs). Research carried out in recent years has identified the anti-proliferative, anti-angiogenic, and immunomodulatory potential of IMIDs [17]. Modulation of the immune system may be the primary mode of action of thalidomide in SS. Thalidomide may act via modulation of cytokine secretion. For example, it is best known for the downregulation of tumor necrosis factor alpha. TH may also decrease levels of IL-1, IL-6 [18] via inhibition of the caspase-1-NLRP3 inflammasome axis [19, 20]. Studies suggest that $\mathrm{TH}$ affects neutrophil chemotaxis and inhibits granulocyte-mediated tissue injury [21, 22]. Inhibition of phagocytosis and reduced expression of matrix metalloproteinases (MMP) may also translate into the efficacy of TH in ND $[16,18,23]$.

Only a handful of reports have described the use of thalidomide in SS [8, 24]. It has mainly been used in patients with the hemopathy-associated form because of steroid-dependency or refractoriness to other drugs. In the vast majority of cases, it shows high effectiveness. Unfortunately, despite an excellent response, $\mathrm{TH}$ also causes a high drop-out rate due to adverse events.

Two important observations emerge from our case. Firstly, knowledge of the specific phenotype of hemopathy-associated SS prompted us to closely and regularly monitor the patient and then introduce increasingly invasive procedures (trephine biopsy) when blood parameters just reached the threshold considered to be diagnostic for MDS. Secondly, it is increasingly acknowledged that MDS and autoimmune and inflammatory diseases (AIDs) are interconnected and reciprocally influence each other [25]. Due to substantial cross-talk between the mediators and cytokines in the local tumor microenvironment and systemic circulation, it is plausible to assume that targeting of cancer-related inflammation has the potential to affect both the underlying neoplasm and the associated skin disease [26].

We believe that thalidomide, at its lowest but effective dose, allowed for control of both diseases without any adverse events. Notably, $25 \mathrm{mg}$ daily dosing of $\mathrm{TH}$ has been considered relatively safe in respect to neuropathy [27]. Another point is that even low or ultra-low doses of thalidomide could be a valuable option in anemic MDS patients [28].

\section{Conclusions}

The presented case emphasizes the importance of including myelodysplastic syndrome into the diagnostic work-up in patients with SS. While most patients with SS respond to corticosteroid therapy, treatment of the disease in the setting of myeloid malignancy can be challenging, with a high incidence of steroid dependence and relapse. Thalidomide should be considered as an alternative, third-line agent in the treatment of such patients.

\section{Authors' contributions}

BW - article concept, data collection, writing of article. DK - critical revision of article, final approval of article. DJ, AP, JS - critical revision of article. JS - pathomorphological analysis.

\section{Conflicts of interest}

The authors declare that they have no conflict of interest.

\section{Financial support \\ None.}

\section{Ethics}

The work described in this article has been carried out in accordance with the Code of Ethics of the World Medical Association (Declaration of Helsinki) for experiments involving humans; EU Directive 2010/63/EU for animal experiments; Uniform Requirements for Manuscripts submitted to Biomedical Journals.

\section{References}

1. Vignon-Pennamen MD. Sweet's syndrome. In: Wallach D, Vignon-Pennamen MD, Valerio Marzano A. ed. Neutrophilic dermatoses. Springer International Publishing, Cham 2018: 13-35.

2. Nelson CA, Stephen $\mathrm{S}$, Ashchyan $\mathrm{HJ}$, et al. Neutrophilic dermatoses: pathogenesis, Sweet syndrome, neutrophilic eccrine hidradenitis, and Behçet disease. J Am Acad Dermatol. 2018; 79(6): 987-1006, doi: 10.1016/j.jaad.2017.11.064, indexed in Pubmed: 29653210.

3. Lepelletier C, Bouaziz JD, Rybojad M, et al. Neutrophilic dermatoses associated with myeloid malignancies. Am J Clin Dermatol. 2019; 20(3): 325-333, doi: 10.1007/s40257-018-00418-2, indexed in Pubmed: 30632096.

4. Hoffbrand AV, Vyas P, Campo E, Haferlach T, Gomez K. Color atlas of clinical hematology. Wiley Blackwell, Hoboken 2018: 256-270.

5. Van Loon K, Gill RM, McMahon P, et al. 20q- clonality in a case of oral sweet syndrome and myelodysplasia. Am J Clin Pathol. 2012; 137(2): 310-315, doi: 10.1309/AJCP917NRWYLTJHV, indexed in Pubmed: 22261459. 
6. Nelson CA, Noe MH, McMahon CM, et al. Sweet syndrome in patients with and without malignancy: a retrospective analysis of 83 patients from a tertiary academic referral center. J Am Acad Dermatol. 2018; 78(2): 303-309.e4, doi: 10.1016/j.jaad.2017.09.013, indexed in Pubmed: 29107342.

7. Kulasekararaj AG, Kordasti S, Basu T, et al. Chronic relapsing remitting Sweet syndrome - a harbinger of myelodysplastic syndrome. Br J Haematol. 2015; 170(5): 649-656, doi: 10.1111/bjh.13485, indexed in Pubmed: 25962438.

8. Vignon-Pennamen MD, Juillard C, Rybojad M, et al. Chronic recurrent lymphocytic Sweet syndrome as a predictive marker of myelodysplasia: a report of 9 cases. Arch Dermatol. 2006; 142(9): 1170-1176, doi: 10.1001/archderm.142.9.1170, indexed in Pubmed: 16983004.

9. Kakaletsis N, Kaiafa G, Savopoulos C, et al. Initially lymphocytic Sweet's syndrome in male patients with myelodysplasia: a distinguished clinicopathological entity? Case report and systematic review of the literature. Acta Haematol. 2014; 132(2): 220-225, doi: 10.1159/000357933, indexed in Pubmed: 24714374.

10. Mekinian A, Grignano E, Braun T, et al. Systemic inflammatory and autoimmune manifestations associated with myelodysplastic syndromes and chronic myelomonocytic leukaemia: a French multicentre retrospective study. Rheumatology (0xford). 2016; 55(2): 291-300, doi: 10.1093/rheumatology/kev294, indexed in Pubmed: 26350487.

11. Navarini AA, Satoh TK, French LE. Neutrophilic dermatoses and autoinflammatory diseases with skin involvement - innate immune disorders. Semin Immunopathol. 2016; 38(1): 45-56, doi: 10.1007/ /s00281-015-0549-6, indexed in Pubmed: 26620372.

12. Fenini G, Contassot E, French LE. Potential of IL-1, IL-18 and inflammasome inhibition for the treatment of inflammatory skin diseases. Front Pharmacol. 2017; 8: 278, doi: 10.3389/fphar.2017.00278, indexed in Pubmed: 28588486.

13. Wallach D, Vignon-Pennamen MD. Pyoderma gangrenosum and Sweet syndrome: the prototypic neutrophilic dermatoses. Br J Dermatol. 2018; 178(3): 595-602, doi: 10.1111/bjd.13955, indexed in Pubmed: 26202386.

14. Barreyro L, Chlon TM, Starczynowski DT. Chronic immune response dysregulation in MDS pathogenesis. Blood. 2018; 132(15): 1553-1560, doi: 10.1182/blood-2018-03-784116, indexed in Pubmed: 30104218.

15. Sallman DA, List A. The central role of inflammatory signaling in the pathogenesis of myelodysplastic syndromes. Blood. 2019; 133(10): 1039-1048, doi: 10.1182/blood-2018-10-844654, indexed in Pubmed: 30670444.

16. Heath MS, Ortega-Loayza AG. Insights into the pathogenesis of Sweet's syndrome. Front Immunol. 2019; 10: 414, doi: 10.3389/ /fimmu.2019.00414, indexed in Pubmed: 30930894.
17. Quach H, Ritchie D, Stewart AK, et al. Mechanism of action of immunomodulatory drugs (IMiDS) in multiple myeloma. Leukemia. 2010; 24(1): 22-32, doi: 10.1038/leu.2009.236, indexed in Pubmed: 19907437.

18. Paravar T, Lee DJ. Thalidomide: mechanisms of action. Int Rev Immunol. 2008; 27(3): 111-135, doi: 10.1080/08830180801911339, indexed in Pubmed: 18437602.

19. Keller M, Sollberger G, Beer HD. Thalidomide inhibits activation of caspase-1. J Immunol. 2009; 183(9): 5593-5599, doi: 10.4049/ /jimmunol.0900476, indexed in Pubmed: 19843943.

20. Lee C, Do HT, Her J, et al. Inflammasome as a promising therapeutic target for cancer. Life Sci. 2019; 231: 116593, doi: 10.1016/j. Ifs.2019.116593, indexed in Pubmed: 31228512.

21. Lee DJ, Li H, Ochoa MT, et al. Integrated pathways for neutrophil recruitment and inflammation in leprosy. J Infect Dis. 2010; 201(4): 558-569, doi: 10.1086/650318, indexed in Pubmed: 20070238.

22. Yasui $\mathrm{K}$, Kobayashi N, Yamazaki T, et al. Thalidomide as an immunotherapeutic agent: the effects on neutrophil-mediated inflammation. Curr Pharm Des. 2005; 11(3): 395-401, doi: 10.2174/1381612053382179, indexed in Pubmed: 15723633.

23. Lauridsen HM, Pellowe AS, Ramanathan A, et al. Tumor necrosis factor- $\alpha$ and IL-17A activation induces pericyte-mediated basement membrane remodeling in human neutrophilic dermatoses. Am J Pathol. 2017; 187(8): 1893-1906, doi: 10.1016/j.ajpath.2017.04.008, indexed in Pubmed: 28609645.

24. Browning CE, Dixon JE, Malone JC, et al. Thalidomide in the treatment of recalcitrant Sweet's syndrome associated with myelodysplasia. J Am Acad Dermatol. 2005; 53(2 Suppl 1): S135-S138, doi: 10.1016/j.jaad.2004.12.041, indexed in Pubmed: 16021163.

25. Fozza C, La Nasa G, Caocci G. The Yin and Yang of myelodysplastic syndromes and autoimmunity: the paradox of autoimmune disorders responding to therapies specific for MDS. Crit Rev Oncol Hematol. 2019; 142: 51-57, doi: 10.1016/j.critrevonc.2019.07.018, indexed in Pubmed: 31376677.

26. Diakos Cl, Charles KA, McMillan DC, et al. Cancer-related inflammation and treatment effectiveness. Lancet Oncol. 2014; 15(11): e493-e503, doi: 10.1016/S1470-2045(14)70263-3, indexed in Pubmed: 25281468.

27. Bastuji-Garin S, Ochonisky S, Bouche P, et al. Thalidomide Neuropathy Study Group. Incidence and risk factors for thalidomide neuropathy: a prospective study of 135 dermatologic patients. J Invest Dermatol. 2002; 119(5): 1020-1026, doi: 10.1046/j.1523-1747.2002.19502.x, indexed in Pubmed: 12445187.

28. Tamburini J, Elie C, Park S, et al. Groupe Francophone des Myélodysplasies, GFM. Effectiveness and tolerance of low to very low dose thalidomide in low-risk myelodysplastic syndromes. Leuk Res. 2009; 33(4): 547-550, doi: 10.1016/j.leukres.2008.06.005, indexed in Pubmed: 18640718. 